\title{
Activation of TRPV1 Mediates Calcitonin Gene-Related Peptide Release, Which Excites Trigeminal Sensory Neurons and Is Attenuated by a Retargeted Botulinum Toxin with Anti-Nociceptive Potential
}

\author{
Jianghui Meng, ${ }^{1}$ Saak V. Ovsepian, ${ }^{1}$ Jiafu Wang, ${ }^{1}$ Mark Pickering, ${ }^{2}$ Astrid Sasse, ${ }^{1}$ K. Roger Aoki, ${ }^{3}$ Gary W. Lawrence, ${ }^{1}$ \\ and J. Oliver Dolly ${ }^{1}$ \\ ${ }^{1}$ International Centre for Neurotherapeutics, Dublin City University, Glasnevin, Dublin 9, Ireland, ${ }^{2}$ Conway Institute of Biomolecular and Biomedical \\ Research, University College Dublin, Dublin 4, Ireland, and ${ }^{3}$ Allergan Inc., Irvine, California 92612
}

\begin{abstract}
Excessive release of inflammatory/pain mediators from peripheral sensory afferents renders nerve endings hyper-responsive, causing central sensitization and chronic pain. Herein, the basal release of proinflammatory calcitonin gene-related peptide (CGRP) was shown to increase the excitability of trigeminal sensory neurons in brainstem slices via CGRP1 receptors because the effect was negated by an antagonist, CGRP8 -37. This excitatory action could be prevented by cleaving synaptosomal-associated protein of $M_{r} 25,000$ (SNAP-25) with botulinum neurotoxin (BoNT) type A, a potent inhibitor of exocytosis. Strikingly, BoNT/A proved unable to abolish the CGRP1 receptor-mediated effect of capsaicin, a nociceptive TRPV1 stimulant, or its elevation of CGRP release from trigeminal ganglionic neurons (TGNs) in culture. Although the latter was also not susceptible to BoNT/E, apparently attributable to a paucity of its acceptors (glycosylated synaptic vesicle protein $2 \mathrm{~A} / \mathrm{B}$ ), this was overcome by using a recombinant chimera (EA) of BoNT/A and BoNT/E. It bound effectively to the C isoform of SV2 abundantly expressed in TGNs and cleaved SNAP-25, indicating that its /A binding domain $\left(\mathrm{H}_{\mathrm{C}}\right)$ mediated uptake of the active /E protease. The efficacy of /EA is attributable to removal of $26 \mathrm{C}$-terminal residues from SNAP-25, precluding formation of SDS-resistant SNARE complexes. In contrast, exocytosis could be evoked after deleting nine of the SNAP-25 residues with /A but only on prolonged elevation of $\left[\mathrm{Ca}^{2+}\right]_{i}$ with capsaicin. This successful targeting of /EA to nociceptive neurons and inhibition of CGRP release in vitro and in situ highlight its potential as a new therapy for sensory dysmodulation and chronic pain.
\end{abstract}

\section{Introduction}

Management of chronic pain poses a major challenge for modern healthcare, because sufferers represent $\sim 20 \%$ of the adult population (Breivik et al., 2006). The creation, referral, and sensation of pain entail complicated and highly sophisticated processes (Scholz and Woolf, 2007). The trigeminal nerve (Vth) innervates nociceptor-rich intracranial structures and transfers signals from the periphery through the afferents to the second-order sensory neurons in the trigeminal nucleus caudalis (TNC). From there, the information is propagated to the ventroposterior thalamic nucleus and then cerebral cortex, in which ultimately the perception of pain occurs (Roper and Brown, 2005). Under certain pathological conditions, the excessive release of certain neuromodulators can cause sensitization of nociceptors, leading to de-

Received Nov. 13, 2008; revised Feb. 20, 2009; accepted March 3, 2009.

This work was supported in part by a Research Professorship Award from Science Foundation Ireland (SFI) (to J.0.D) and a Programme for Research in Third Level Institutions Cycle 4 grant from the Irish Higher Education Authority for "Target-driven therapeutics and theranostics." Dr. Keith Murphy (University College Dublin) is thanked for facilitating the $\mathrm{Ca}^{2+}$ fluorescence measurements, supported by SFI Grant 03/IN3/B403C. We thank Rita Warde for her preparation of this manuscript.

Correspondence should be addressed to J. Oliver Dolly, International Centre for Neurotherapeutics, Dublin City University, Glasnevin, Dublin 9, Ireland. E-mail: oliver.dolly@dcu.ie.

DOI:10.1523/JNEUROSCI.5490-08.2009

Copyright $\odot 2009$ Society for Neuroscience $\quad$ 0270-6474/09/294981-12\$15.00/0 velopment of chronic neuroinflammation with associated sustained pain (Black, 2002). Such a mechanism appears to underlie the hyper-reactivity of meningeal nociceptors in migraines attributable to a disproportionate release of calcitonin gene-related peptide (CGRP) from the trigemino-cerebrovascular system. CGRP is the most abundant pain mediator in trigeminal ganglionic neurons (TGNs), a major sensory relay center (Gulbenkian et al., 2001; Durham et al., 2004). CGRP stimulates extravasation of inflammatory mediators that cause intracranial hypersensitivity and throbbing migraine headache (Burstein et al., 2000; Bolay et al., 2002). Moreover, acute migraine headaches can often be alleviated by CGRP receptor antagonists (e.g., BIBN4096) or serotonin agonists (e.g., triptans), which lower CGRP release (Ferrari et al., 2001; Olesen et al., 2004); the reduction in pain is accompanied by normalization of CGRP levels in cranial venous outflow (Goadsby et al., 1990; Goadsby and Edvinsson, 1993). Accordingly, intravenous infusion of CGRP produces a migraine-like headache in susceptible volunteers (Olesen and Lipton, 2004). A pressing need for therapeutics to treat chronic pain (Scholz and Woolf, 2007) is highlighted by the relatively short half-lives and numerous adverse side effects of pain killers commonly used in clinical practice (nonspecific analgesics/opioids and nonsteroidal anti-inflammatory drugs) (Ballantyne and Mao, 2003; Doods et al., 2007). 
A promising therapeutic candidate has been unveiled by clinical research showing a decrease in the frequency, duration, and intensity of migraine after administration of botulinum toxin $\mathrm{A}$ complex (BOTOX) (Binder et al., 2000). BOTOX offers the advantages of having a much longer action and greater potency in blocking the release of transmitters and inflammatory/pain mediators via cleavage of SNAP-25, a 206-residue SNARE protein essential for neuroexocytosis (de Paiva et al., 1993). However, additional investigations are required to find a molecular basis for its beneficial effects in some migraineurs (Silberstein et al., 2000; Mauskop, 2002), which are not consistently observed (for review, see Naumann et al., 2008). This raises the related and pertinent question of why botulinum neurotoxin type A (BoNT/A) fails to block CGRP release from TGNs evoked by a nociceptive C-fiber stimulant, capsaicin, despite inhibiting this exocytosis when triggered by $\mathrm{K}^{+}$or bradykinin (Meng et al., 2007).

It is shown herein that, in contrast to BoNT/A and /E, a novel chimera (EA) of / A and /E serotypes inhibits CGRP release from TGNs and eliminates the excitatory effects of this peptide in brainstem sensory neurons evoked by capsaicin, which activates the transient receptor potential vanilloid receptor type 1 (TRPV1). CGRP exocytosis elicited by this TRPV1 agonist was found to require residues 180-197 of SNAP-25 but not the nine C-terminal amino acids removed by BoNT/A. Effective inhibition of this release by /EA seems to arise from a combination of binding to the sensory neurons via synaptic vesicle protein (SV2) $\mathrm{C}$ isoform and the resultant internalized /E protease preventing the formation of stable SNARE complexes. Such unique and multiple properties of EA indicate its anti-nociceptive potential with implications for chronic pain therapy.

\section{Materials and Methods}

Materials. Suppliers of cell culture materials and the various antibodies used [except Syt-Ecto antibody (clone 604.2) bought from Synaptic Systems] were listed previously (Meng et al., 2007; Wang et al., 2008). Capsaicin, bradykinin, ionomycin, kynurenic acid, picrotoxin, and strychnine were obtained from Sigma. Glutathione Sepharose 4 Fast Flow and ${ }^{45} \mathrm{Ca}^{2+}$ were purchased from GE Healthcare. Homogeneous, fully active di-chain (DC) BoNT/A,/D partially nicked and BoNT/E as a purified single chain (SC) were purchased from Metabiologics; /E was proteolytically nicked to the DC form (>95\%) (Wang et al., 2008). Fluo-4 AM and PBS were supplied by Invitrogen. Ganglioside mixture extracted from bovine gray matter containing approximately the following: $18 \% \mathrm{GM} 1$, $55 \%$ GD1a, $15 \%$ GD1b, $10 \%$ GT1b, and 2\% of other gangliosides were bought from Calbiochem. Experimentation with genetically modified organisms and BoNTs were performed in accordance with European Union regulations and registered with the Irish Environmental Protection Agency and Health and Safety Authority.

Animals. Housing/handling of rats (Sprague Dawley) and experimental procedures had been approved by the Dublin City University Ethics Committee and the Irish Authorities (Meng et al., 2007).

Cell culture and exocytosis/endocytosis assay. Cerebellar granule neurons (CGNs) and TGNs were isolated from rats and cultured as described previously (Foran et al., 2003; Meng et al., 2007). Basal and stimulated (by $60 \mathrm{~mm} \mathrm{~K}^{+}, 1 \mu \mathrm{M}$ capsaicin, or $0.1 \mu \mathrm{M}$ bradykinin) release of CGRP from TGNs were quantified as before (Meng et al., 2007), except for including ionomycin $(5 \mu \mathrm{M})$ or vehicle $(0.05 \%$ DMSO) in some experiments. Cleavage of SNAREs by the toxins was quantified as described previously (Meng et al., 2007). Exocytosis/endocytosis was assessed in TGNs cultured on coverslips and incubated with $100 \mathrm{~nm}$ BoNT/A or /EA for $24 \mathrm{~h}$, before washing and exposure to Syt-Ecto antibody ( $1: 100)$ for 15 min in basal release and stimulation buffers. After washing thrice with basal buffer, cells were fixed, and images were captured on an Olympus IX71 microscope equipped with a CCD camera (Meng et al., 2007).

Immunofluorescent staining of CGRP in brainstem slices. Rats [postnatal day 30 (P30)] were deeply anesthetized (sodium pentobarbital at $50 \mathrm{mg} /$ $\mathrm{kg}$ ) and perfused transcardially with $150 \mathrm{ml}$ of PBS, pH 7.2, followed by a fixative [ $150 \mathrm{ml} 4 \%$ paraformaldehyde (PFA) in PBS]. The brainstem was dissected, kept in $4 \%$ PFA overnight, and cryoprotected by $24 \mathrm{~h}\left(4^{\circ} \mathrm{C}\right)$ incubation in $30 \%$ sucrose; coronal sections $(50 \mu \mathrm{m})$ were cut on a cryostat and collected free floating in PBS. After rinsing, the slices were placed in $4 \%$ horse serum $(1 \mathrm{~h}$ ) before permeabilization with $0.2 \%$ Triton X-100 for 2 min. Rabbit antibodies to CGRP (1:2000) in 0.02\% Triton $\mathrm{X}-100$ containing PBS were applied for $24 \mathrm{~h}$ before the samples were rinsed and incubated with cyanine 3 -conjugated anti-rabbit secondary antibody (1:500). The intensity of fluorescence staining was monitored every $2 \mathrm{~h}$; after reaching a desirable intensity, slices were extensively washed with PBS, dried, and fixed with Vectashield. Microscopic images were recorded as indicated above.

Measurements of $\mathrm{Ca}^{2+}$ dynamics and ${ }^{45} \mathrm{Ca}^{2+}$ uptake into TGNs. Coverslips containing TGNs were loaded with $3 \mu \mathrm{M}$ Fluo-4 AM in basal release HEPES buffer saline [BR-HBS (in mM): 22.5 HEPES, pH 7.4, 3.5 $\mathrm{KCl}, 1 \mathrm{MgCl}_{2}, 2.5 \mathrm{CaCl}_{2}, 3.3$ glucose, and $0.1 \%$ bovine serum albumin (BSA)] (Meng et al., 2007) at room temperature for $20 \mathrm{~min}$ and mounted on a custom-built low-volume $(350 \mu \mathrm{l})$ chamber attached to an Axioskop 2 FS MOT/LSM Pascal confocal microscope (Zeiss). An argon laser was used to excite the fluorophore at $488 \mathrm{~nm}$. Serial images of fluorescent signals were grabbed every $10 \mathrm{~s}$, whereas the superfusate was switched after $\sim 2$ min from BR-HBS to stimulation buffer containing either 60 $\mathrm{mm} \mathrm{K}^{+}$or $1 \mu \mathrm{M}$ capsaicin. The intensity of fluorescence at $505-530 \mathrm{~nm}$ $(f)$ was analyzed offline on a cell-by-cell basis and expressed relative to the baseline fluorescence $\left(f_{0}\right)$ measured for each cell in BR-HBS. Mean \pm SEM was plotted against time; $n$ values are given in the figure legends.

For assessment of $\mathrm{Ca}^{2+}$ uptake, TGNs were incubated with $24 \mu \mathrm{Ci} / \mathrm{ml}$ ${ }^{45} \mathrm{Ca}^{2+}$ in BR-HBS containing $0.1 \%$ ethanol, $1 \mu \mathrm{M}$ capsaicin, or $60 \mathrm{~mm}$ $\mathrm{K}^{+}$at room temperature for the times indicated in the figures before stopping the incubation by six washes in $1 \mathrm{ml}$ of BR-HBS. The cells were solubilized in $200 \mu \mathrm{l}$ of $0.1 \%$ SDS and counted in Beckman Coulter CP scintillation spectrometer. $\mathrm{Ca}^{2+}$ uptake was calculated from a standard curve of known amounts of ${ }^{45} \mathrm{Ca}^{2+}$ against counts per minute.

Expression and purification of recombinant proteins and glutathione S-transferase pull-down assay. Expression and purification of chimera EA are described elsewhere (Wang et al., 2008). Glutathione S-transferase (GST)-tagged SV2C-L4 fusion protein was generated from pCMV SV2C (Dong et al., 2006), expressed, and incubated with glutathione Sepharose 4 Fast Flow resin. The pull-down assay was performed as outlined previously (Dong et al., 2006). GST-fusion protein $(\sim 100 \mu \mathrm{g})$ immobilized on $100 \mu \mathrm{l}$ of glutathione Sepharose was incubated for $4 \mathrm{~h}$ at $4^{\circ} \mathrm{C}$ with BoNTs (100 nM) in $100 \mu \mathrm{l}$ of binding buffer containing $0.6 \mathrm{mg} / \mathrm{ml}$ of a ganglioside mixture. After washing, bound proteins were eluted by $2 \times$ lithium dodecylsulfate (LDS) sample buffer and analyzed using precast NuPAGE $4-12 \%$ Bis-Tris gels; toxins or acceptor proteins were subsequently detected by Western blotting with IgGs against SV2C, LC/E, or BoNT/A.

Two-dimensional gel electrophoresis. A two-dimensional SDS-PAGE method (Lawrence and Dolly, 2002) was used to investigate whether cleaved SNAP-25 products were present in SDS-resistant SNARE complexes from TGNs treated with BoNT/A or /EA. After stimulation with 1 $\mu \mathrm{M}$ capsaicin for $30 \mathrm{~min}$ at $37^{\circ} \mathrm{C}$, the cells were solubilized in LDS sample buffer without boiling. Proteins were separated by SDS-PAGE on $4-12 \%$ precast Bis-Tris gel, and each sample lane was cut into strips corresponding to different distances of migration. Small pieces of the chopped gels were boiled for $10 \mathrm{~min}$ in LDS sample buffer, left overnight at room temperature, and boiled again for 5 min before loading the extracted proteins onto a second $12 \%$ precast Bis-Tris gel. After re-electrophoresis and transfer to polyvinylidene difluoride, SNAREs released from the complexes after boiling were detected by Western blotting.

Electrophysiological recordings from brain slice. A modification of the technique (Hamill et al., 1981) for recording from brainstem slices of rats (P14-P18) was used. In brief, under deep anesthesia (ketamine, 100 $\mathrm{mg} / \mathrm{kg}$, i.p.), animals were decapitated, and the brainstem was dissected, hemisected, and then immersed in ice-cold artificial CSF (ACSF) [in mM: 75 sucrose, $85 \mathrm{NaCl}, 2.5 \mathrm{KCl}, 1.25 \mathrm{NaH}_{2} \mathrm{PO}_{4}, 25 \mathrm{NaHCO}_{3}, 0.5 \mathrm{CaCl}_{2}, 4$ $\mathrm{MgCl}_{2}$, and 25 glucose (bubbled with $95 \% \mathrm{O}_{2}, 5 \% \mathrm{CO}_{2}$ )]. Coronal slices $(300 \mu \mathrm{m})$ were cut from the brainstem caudal from the obex and transferred to the incubation chamber (room temperature) containing ACSF 
except lacking sucrose and the $[\mathrm{NaCl}]$ was increased to $125 \mathrm{~mm}$. After 30 min incubation (bubbling with $95 \% \mathrm{O}_{2}, 5 \% \mathrm{CO}_{2}$ ), slices were transferred to the recording solution [in mM: $125 \mathrm{NaCl}, 2.5 \mathrm{KCl}, 1.25 \mathrm{NaH}_{2} \mathrm{PO}_{4}, 25$ $\mathrm{NaHCO}_{3}, 1.5 \mathrm{CaCl}_{2}, 2 \mathrm{MgCl}_{2}$ and 25 glucose (bubbled with $95 \% \mathrm{O}_{2}, 5 \%$ $\left.\mathrm{CO}_{2}\right)$ ] and kept there until used. The effects of toxins were monitored in slices incubated for $2 \mathrm{~h}$ in ACSF containing $100 \mathrm{~nm}$ BoNT/A or /EA before recordings, with oxygen blown over the surface of the fluid.

Whole-cell recordings from slices were performed under continual perfusion at $32-34^{\circ} \mathrm{C}$. Current- and voltage-clamp measurements were made from neurons within the superficial layers of TNC (Vc, II-IV laminas, viewed with an Olympus BX51WI microscope, differential interference contrast), a region known to process $\mathrm{A} \delta$ and $\mathrm{C}$ afferent inputs from the entire trigeminal area (Sugimoto et al., 1997; Carstens et al., 1998; Hiura et al., 1999; Bae et al., 2004). An EPC-10 amplifier (HEKA) was used for electrophysiological recordings. For current-clamp experiments, patch pipettes were filled with internal solution containing 140 mм $\mathrm{KCH}_{3} \mathrm{O}_{3} \mathrm{~S}, 10 \mathrm{~mm} \mathrm{KCl}, 5 \mathrm{~mm} \mathrm{NaCl}, 2$ mм MgATP, 0.01 mм EGTA, and $10 \mathrm{~mm}$ HEPES, pH 7.3, with $280 \mathrm{mOsm} / \mathrm{L}, R_{\text {inp }}$ of 3-7 M . Glutamate, GABA, and glycine receptor antagonists ( $5 \mathrm{~mm}$ kynurenic acid, 200 $\mu \mathrm{M}$ picrotoxin, and $1 \mu \mathrm{M}$ strychnine, respectively) were added routinely to the perfusate. Recordings were corrected for liquid junction potentials $(6 \mathrm{mV}) . C_{\mathrm{m}}$ and $R_{\mathrm{s}}$ compensation were cancelled using a protocol built-in PatchMaster. For voltage-clamp experiments (holding potential of $-75 \mathrm{mV}$ ), pipettes were filled with an internal solution containing 100 mu K-gluconate, $13 \mathrm{~mm} \mathrm{KCl}, 9 \mathrm{~mm} \mathrm{MgCl}_{2}, 0.07 \mathrm{~mm} \mathrm{CaCl}_{2}, 10 \mathrm{~mm}$ EGTA, $10 \mathrm{~mm}$ HEPES, $2 \mathrm{~mm} \mathrm{Na}_{2}$-ATP, and $0.4 \mathrm{~mm} \mathrm{Na-GTP,} \mathrm{pH} \mathrm{7.4,} 280$ $\mathrm{mOsm} / \mathrm{L}$. Signals were filtered at $1-5 \mathrm{kHz}$, digitized at $10-20 \mathrm{kHz}$, and analyzed offline (FitMaster; HEKA). Spikes were elicited by depolarizing of current pulses from a holding potential of $\sim 70 \pm 2 \mathrm{mV}$. The latency of spiking was determined based on time difference between the onset of stimulus and the peak of the first spike; spike numbers were counted over the period of depolarizing current injection. The current threshold for eliciting spikes represents the minimal current that triggered spiking; the membrane potential at which the spike upstroke rate $(\mathrm{d} V / \mathrm{d} t)$ exceeded 5 $\mathrm{V} / \mathrm{s}$ was taken as a voltage threshold (Ovsepian and Friel, 2008). Input resistance/conductance $\left(G_{\text {input }}=I / R_{\text {input }}\right)$ was measured based on steady membrane voltage responses to small hyperpolarizing current pulses.

Statistical analysis. Data were calculated and graphs generated by GraphPad Prism 4.0 or IgorPro; each point represents the mean \pm SEM. Statistical significance was assessed using paired or unpaired Student's two-tailed $t$ tests, with $p<0.05$ defining a significant difference.

\section{Results}

\section{Endogenous CGRP enhances the excitability of delayed spiking sensory neurons in TNC, an effect abolished by BoNT/A}

Although significant evidence exists for the importance of CGRP in sensory processing of trigeminal nociceptors during migraine (see Introduction), little is known about the central action of this peptide on the processing of sensory inputs in the trigeminal complex. Toward this end, effects of CGRP were examined on brainstem Vc neurons receiving profuse inputs from CGRPpositive trigeminal afferents (Fig. $1 A$ ), which have been characterized as delayed spiking neurons (DSNs) (Sedlacek et al., 2007). After bath application of CGRP (500 nM), these DSNs accelerate their evoked firing ( $36 \pm 6 \%$ reduction of the spike onset delay at $I_{\text {injected }}=1.5 \times$ threshold intensity; $n=6$ ), without noticeable change in the resting membrane potential/current and action potential (AP) waveforms (Fig. $1 B, C, F$ ). The enhanced firing was accompanied by an $\sim 25 \%$ reduction in current (but not voltage) threshold for eliciting spike trains and an increase in the number of APs (Fig. $1 E, G, H$ ). These changes were not seen with a lower CGRP dose ( $50 \mathrm{nM} ; n=4$; data not shown). Consistent with these effect of CGRP, blockade of CGRP1 receptors with 1 $\mu \mathrm{M}$ CGRP8-37 (Poyner, 1995; Wimalawansa, 1996) substantially extended the delay before the onset of evoked spikes $(22 \pm$ $9 \%$ increase in the delay at $I_{\text {injected }}=1.5 \times$ threshold intensity; $n=5)$ and reduced the overall spike number at the same stimulus intensity (Fig. $1 D-F$ ). Antagonism of CGRP1 receptors caused a small but significant increase in current threshold for eliciting spikes, whereas the voltage threshold remained virtually unchanged (Fig. 1G,H). The effect of CGRP8-37 on spike onset and AP number developed gradually, leveling at 10-12 min perfusion, and was slightly reversed (by $11 \pm 7.3$ and $2.1 \pm$ $1.3 \%$ for spike onset delay and number, respectively) when CGRP8-37 was coapplied with $500 \mathrm{~nm}$ CGRP for $15 \mathrm{~min}(n=$ $4 ; p>0.05)$ (Fig. $1 I-K)$. These observations indicate a significant basal CGRP drive in Vc nucleus of acute brainstem slices, which noticeably facilitates the electroresponsiveness of DSNs in the trigeminal complex.

Next, the effect of BoNT/A on this basal CGRP drive in DSNs was evaluated. In contrast to the above-noted results from control experiments (Fig. 1D), treatment of slices with CGRP8-37 for $15 \mathrm{~min}$ after their incubation in /A caused no significant alteration in the delay of spike train onset $(6.3 \pm 7 \%$ increase in the delay; $n=5 ; p>0.05)$ or in spike number $(14.2 \pm 13.3 \%$ reduction) at $I_{\text {injected }}=1.5 \times$ threshold intensity stimulus (Fig. $2 \mathrm{~A}$ ). Consistently, blockade of CGRP1 receptors did not cause a significant change in the current thresholds for spiking in /A-treated slices, although the overall stimulus intensity for eliciting spikes was significantly enhanced (38.2 $\pm 9 \%$ ) (Fig. 2D). Furthermore, when compared with controls, the BoNT/A-treated neurons exhibited a steeper $1 / R_{\text {input }}$ relation at near-threshold current pulses, suggestive of a larger transient membrane conductance during depolarization (Fig. 2C).

\section{Retargeted chimera EA, but not the parental toxins, blocks capsaicin-induced CGRP release and vesicle recycling in sensory neurons}

In view of the inhibition by BoNT/A of basal CGRP drive in DSNs and its near-complete inhibition of $\mathrm{K}^{+}$- or bradykinin-evoked release of this peptide from TGNs, it was curious that capsaicinmediated CGRP exocytosis proved resistant to /A (Meng et al., 2007). This raised the question of whether blockade of capsaicinstimulated CGRP release could be achieved by deleting 26 C-terminal residues from SNAP-25 with BoNT/E instead of only nine by /A. Surprisingly, /E proved relatively ineffective on TGNs, as reflected by the minimal SNAP-25 cleavage (Fig. $3 A$ ) and no reduction in either $1 \mu \mathrm{M}$ capsaicin- or $60 \mathrm{mM} \mathrm{K}^{+}$-triggered CGRP release (Fig. $3 B$ ), despite its well established rapid internalization and greater potency in blocking exocytosis from other neuron types (Foran et al., 2003; Keller et al., 2004). Because glycosylated SV2A and B, but not C, have been identified as BoNT/E acceptors (Dong et al., 2008), their relative contents in TGNs compared with CGNs were assessed by Western blotting using isoform-specific antibodies. Interestingly, SV2A and B were found to be expressed at significantly lower levels in TGNs than CGNs (Fig. 3B, inset), consistent with these sensory neurons being /E insensitive. In contrast, SV2C isoform, the prime acceptor for /A (Mahrhold et al., 2006), was relatively abundant in TGNs (Fig. 3B, inset), which accords with the susceptibility of their SNAP-25 to cleavage by /A (Meng et al., 2007). Thus, an alternative strategy was adapted to examine the role of SNAP-25 in capsaicin-evoked CGRP release. As a C-terminal moiety, $\mathrm{H}_{\mathrm{C}}$, of BoNT/A binds to SV2C at the cell surface, delivery of the BoNT/E protease [i.e., its light chain (LC)] into TGNs was attempted by swapping its binding domain with the corresponding region of /A. This used a recombinant chimera (EA) of BoNT/A and $/ \mathrm{E}$, containing the $\mathrm{LC}$ and the $\mathrm{N}$-terminal portion of the heavy chain $\left(\mathrm{H}_{\mathrm{N}}\right)$ of /E ligated to the $\mathrm{H}_{\mathrm{C}}$ from /A, that had been 

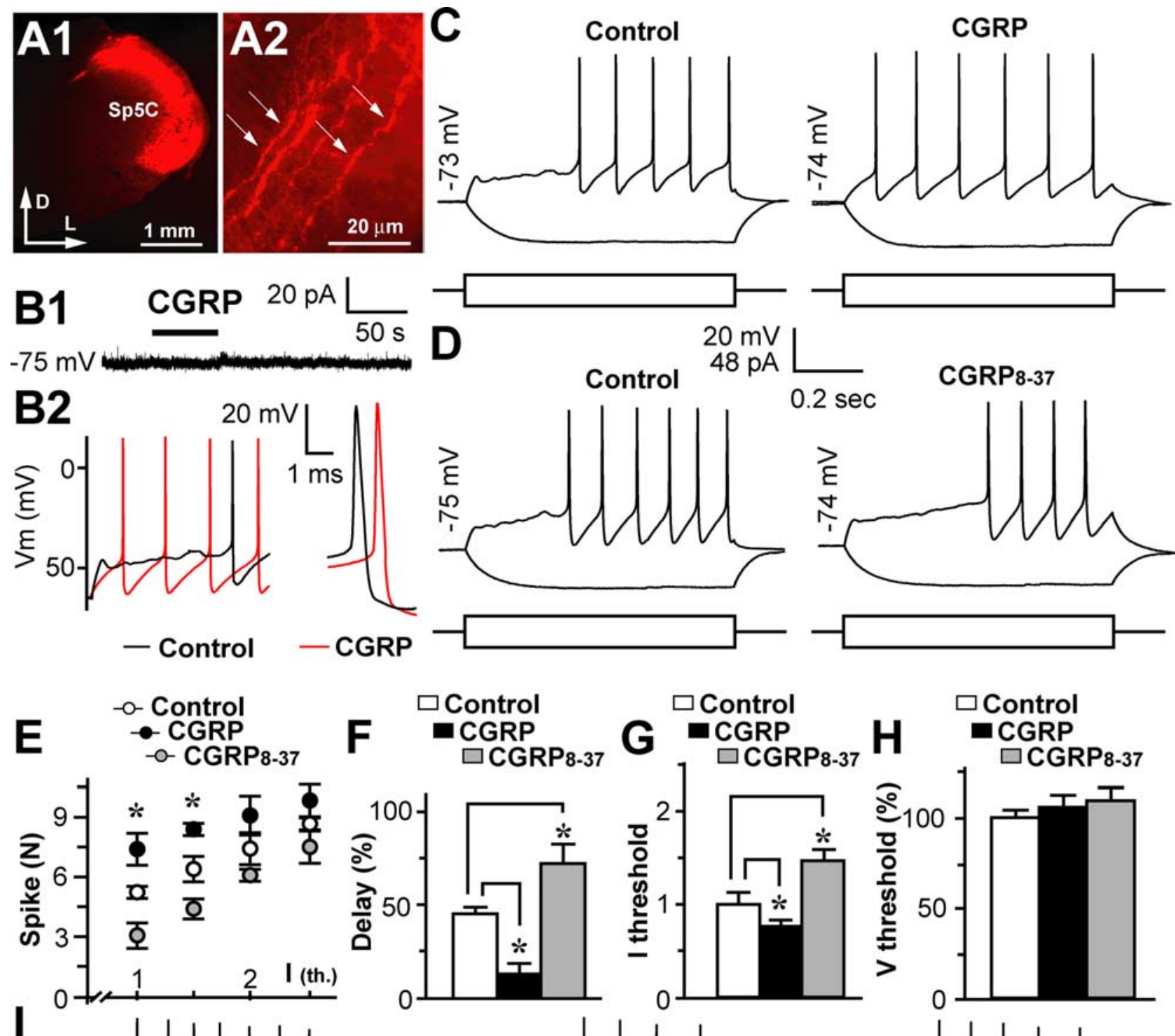

口CGRP8-37

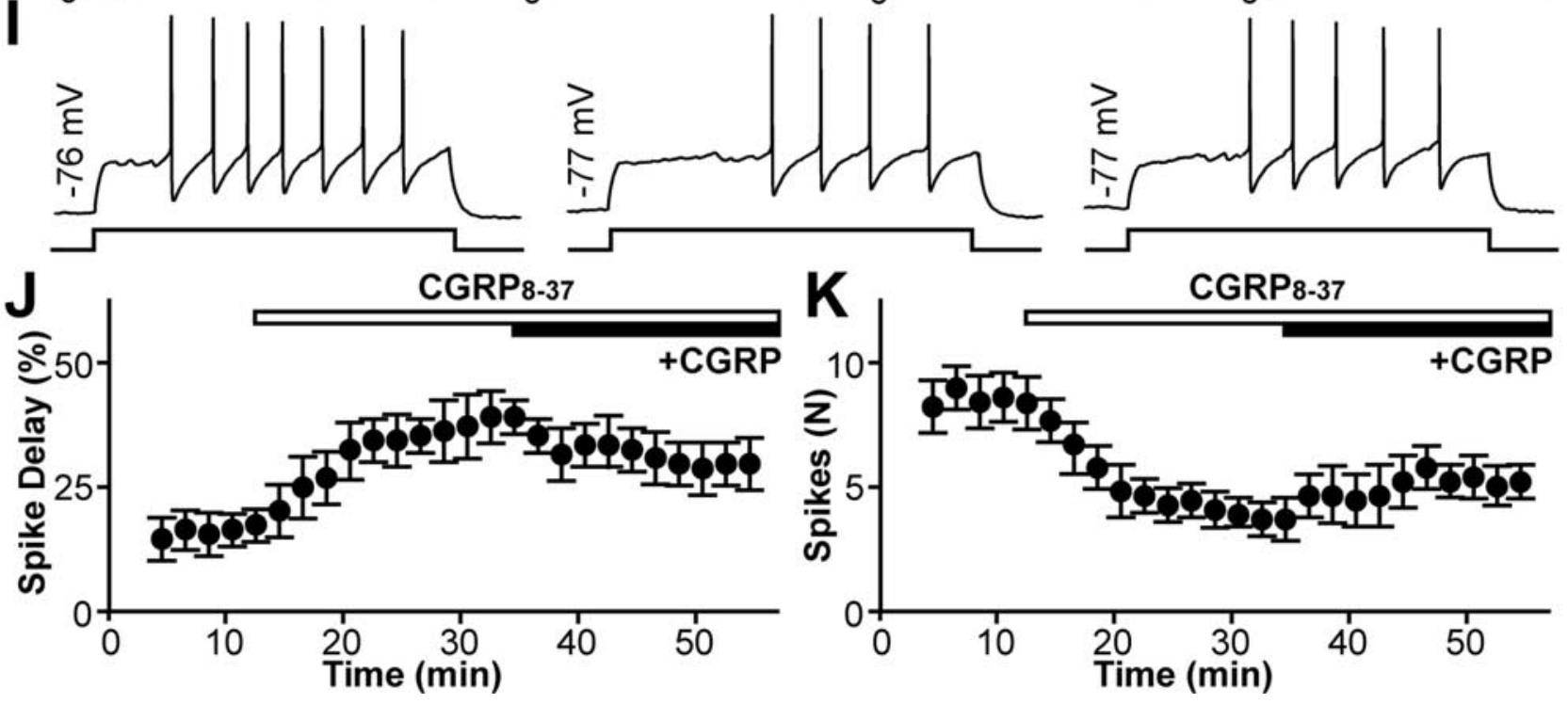

Figure 1. Immunofluorescence staining of CGRP in trigeminal sensory neurons (Vc nucleus) and its effect on evoked firing of DSNs. $\mathbf{A}$, $\boldsymbol{A 2}$, Immunostaining of CGRP in Sp5C of medulla oblongata in $50 \mu \mathrm{m}$ coronal brainstem sections; note that the CGRP signal is highly localized in axons and varicosities (A2). D and $\mathrm{L}$ denote dorsal and lateral. $\boldsymbol{B}, \boldsymbol{C}, \mathrm{CGRP}$ does not alter resting membrane current in DSNs (holding potential, $-75 \mathrm{mV}$, top trace; thick bar illustrates the duration of CGRP application, $500 \mathrm{~nm}$ ) (B1) but accelerates evoked spiking (from $480 \pm 37$ to $35 \pm 45 \mathrm{~ms}$ before and after $I_{\text {injected }}=1.5 \times$ threshold intensity) and increases the spike number ( $6.2 \pm 0.7$ vs $8.1 \pm 0.2$ before and after (GRP; $n=6 ; p<0.05$ ), altering the AP waveforms (bottom traces and $\boldsymbol{B} 2$ and $\boldsymbol{C}$ ). Black and red traces under control conditions and in the presence of CGRP are superimposed. $D$, Blockade of CGRP1 receptors by CGRP $8-37$ slows the onset of evoked firing (to $705 \pm 74$ ms; $p<0.05$ ) and reduces the AP number (to $4.5 \pm 0.5 ; p<0.05$ ) in DSNs. $E, F$, Plot of spike number $(N) /$ current stimulus and spike onset delay histogram (stimulus intensity $=1.5 \times($ Figure legend continues.) 


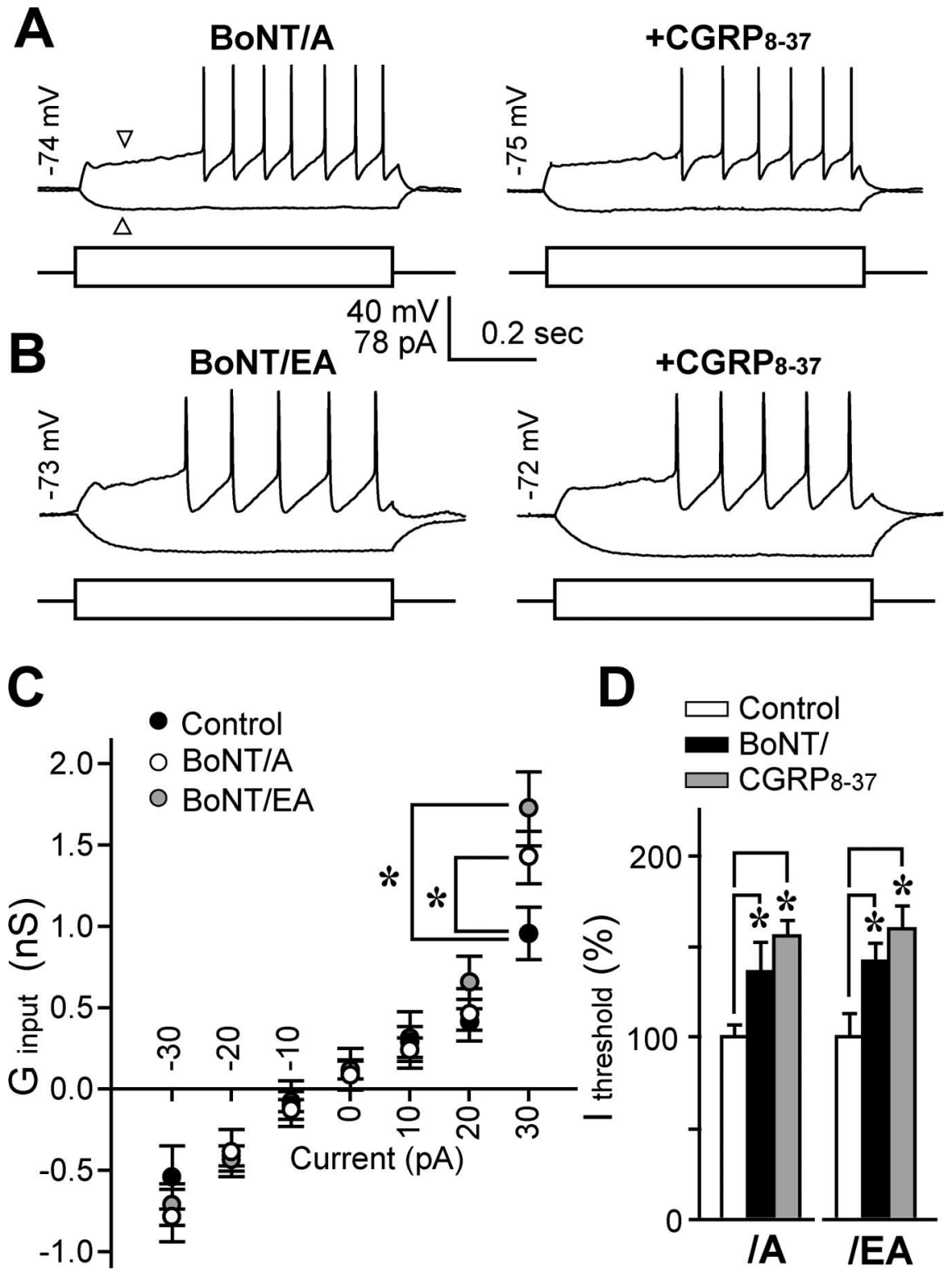

Figure 2. BoNT/A and /EA inhibit basal excitatory drive of CGRP in Vc DSNs and lower their excitability. $A, B$, Current pulse evoked responses ( $1.5 \times$ threshold intensity) in typical DSNs after incubation with BoNT/A or /EA; note that, in slices pretreated with / $A$ or /EA, blockade of CGRP1 receptors failed to change the evoked firing response (spike latency; $448 \pm 79 \mathrm{vs} 419 \pm 80 \mathrm{~ms}$; number of spikes, $6.6 \pm 3$ vs $7.0 \pm 2.2 ; n=5 ; p>0.05$ ). $C, G-/$ plot of the steady-state voltage responses (average voltage over $100 \mathrm{~ms}$ after steady plateau potential was reached, white arrow in $A$ ) to constant hyperdepolarizing and depolarizing current steps (1 s duration). A matching of $\mathrm{G}-/$ relation at more negative voltages and deviation of membrane conductance between test and control groups at more positive potentials indicate activation of larger voltage-activated conductance in the toxin-treated slices during depolarization. $D$, Comparison of the threshold current intensity between $/ A$ - and /EA-treated cells ( $n=5$ for each group) with controls $(n=12)$, from a holding potential of approximately $-75 \mathrm{mV}$; intensities of threshold current of controls are taken as $100 \%$. ${ }^{*}<0.05$ when compared with control. expressed as an SC in Escherichia coli, purified, and converted to the fully active DC form (Wang et al., 2008). As expected, the EA protein had acquired the binding selectivity of BoNT/A judging by its interaction with the fourth intralumenal loop of SV2C and gangliosides (Fig. 3E), which mimic the synaptic acceptor for /A (Dong et al., 2006; Mahrhold et al., 2006). The presence of /E-like protease activity in /EA was revealed by its cleavage of a model substrate green fluorescent protein (GFP)SNAP-25 (134-206)-His6 (Wang et al., 2008), which yielded a fragment that comigrated on SDS-PAGE with the product of BoNT/E but not /A (Fig. 3F). Notably, /EA readily entered cultured TGNs, as demonstrated by its cleavage of SNAP-25; the cells were $>1000$-fold more susceptible to the chimera (Fig. 3C,D) than BoNT/E (Fig. $3 A, B$ ), with $\mathrm{EC}_{50}$ values being $\sim 1 \mathrm{~nm}$ and $\gg 1 \mu \mathrm{M}$, respectively. Accordingly, /EA caused a dose-dependent inhibition of CGRP release elicited by $\mathrm{K}^{+}$ depolarization or bradykinin (Fig. 3D); the $\mathrm{IC}_{50}(0.8 \mathrm{nM})$ for the latter corresponds more closely to the level of SNAP-25 cleavage than the value for $\mathrm{K}^{+}$-evoked exocytosis. Importantly, the release of CGRP stimulated by capsaicin was blocked by pretreatment with /EA (Fig. 3D), in contrast to the above-noted ineffectiveness of BoNT/E or /A. Although its potency $\left(\mathrm{IC}_{50}\right.$ $\sim 10 \mathrm{nM}$ ) was somewhat lower than that for other stimuli, this inhibition established conclusively an involvement of SNAP-25 in release of this pain mediator following activation of TRPV1. To ascertain whether the efflux of other transmitters also relies on this SNARE protein, the trafficking of exocytotic vesicles to the cell surface was monitored. Binding to TGNs of a monoclonal antibody directed against an intravesicular domain of synaptotagmin 1 (Syt-Ecto) was stimulated by $60 \mathrm{~mm}$ $\mathrm{K}^{+}$or $1 \mu \mathrm{M}$ capsaicin (Fig. 4), reflecting increased vesicle fusion with the plasmalemma. /EA prevented both capsaicintriggered exposure of the Syt-Ecto epitope as well as that elicited by depolarization (Fig. 4). Although BoNT/A prevented the enhancement of Syt-Ecto binding by $\mathrm{K}^{+}$ depolarization, the increase in binding elicited by capsaicin remained unaltered (Fig. 4), consistent with the feeble inhibition by the toxin of CGRP release elicited by this stimulus (Meng et al., 2007).

(Figure legend continued.) threshold). ${ }^{*} p<0.05$. Note that differences in AP number gradu decline with increase in stimulus intensity. $\mathbf{G}, \boldsymbol{H}$, Summary plots of current threshold for eliciting spike trains and voltage threshold for spike initiation under control conditions $(n=12)$, in the presence of CGRP ( $n=6)$ and after blockade of CGRP1 receptors by CGRP8 $-37(n=5)$. I-K, Time courses of the effect of CGRP8 -37 coapplied with CGRP on the delay of spike-train onset and number of spikes. Representative traces $(n=4)$ of evoked firing under control conditions ( $\boldsymbol{I}$, left), after 15 min application of CGRP8 -37 (middle) and CGRP8 - 37 plus CGRP (right). Note, blockade of CGRP1 receptors gradually increases the delay of evoked spike onset and lowers the spike number with little effect of CGRP when applied in the presence of the blocker.
Only /EA inhibits capsaicin-induced CGRP drive in slices Electrophysiological recordings were used to ascertain whether /EA and /A exert comparable effects on basal CGRP drive in DSNs in situ compared with those in cultured TGNs. As seen with BoNT/A (Fig. 2A, C,D), no significant effects of CGRP8-37 on evoked firing were seen in slices preincubated with /EA (Fig. $2 B$ ), 
A

$$
\text { BoNT/E (nM) }
$$

$\begin{array}{llllllll}0 & 0.01 & 0.1 & 1 & 10 & 100 & 1000\end{array}$
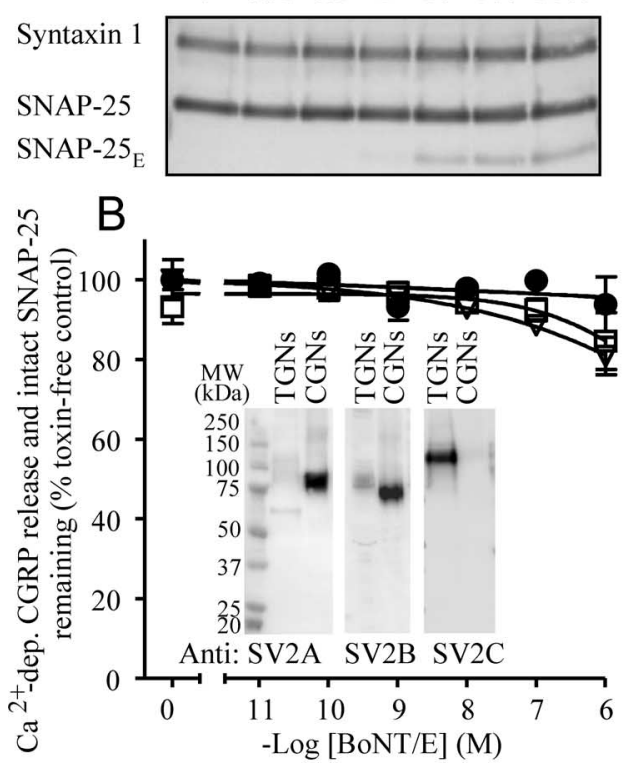

C Chimera EA $(\mathrm{nM})$ $\begin{array}{llllllll}0 & 0.01 & 0.1 & 1 & 10 & 100 & 1000\end{array}$

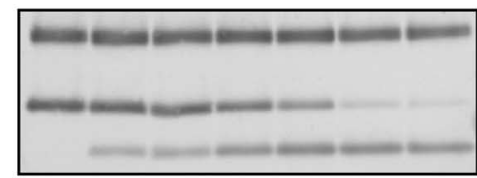

D

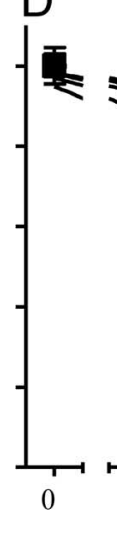

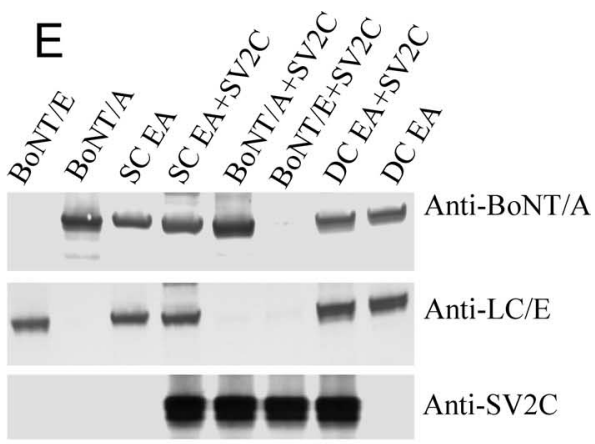

$\mathrm{F}$

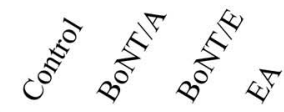

Figure 3. Insensitivity of TGNs to BoNT/E is attributable to a paucity of its acceptors and can be overcome by using chimera EA, which binds to SV2C - L4, enters TGNs, and blocks CGRP release evoked by all stimuli. Rat cultured TGNs at $7 \mathrm{~d}$ in vitro were exposed to BoNT/E $(\boldsymbol{A}, \boldsymbol{B})$ or $\mathrm{EA}(\boldsymbol{C}, \boldsymbol{D})$ at $37^{\circ} \mathrm{C}$ for 24 and $12 \mathrm{~h}$, respectively. Release of $\left(G R P(B, D)\right.$ evoked over 30 min at $37^{\circ} \mathrm{C}$ by bradykinin $(\mathbf{\Delta}), 60 \mathrm{~mm} \mathrm{~K}^{+}(\square)$, or $1 \mu \mathrm{m}$ capsaicin $(-)$ was measured before subjecting the cells to SDS-PAGE and Western blotting of intact and truncated SNAP-25 (A, $C$ ). The proportions of intact substrate remaining $(\boldsymbol{B}, \boldsymbol{D}, \nabla)$ were calculated from digital images of the gels; note that some symbols are overlapped. Inset in $\boldsymbol{B}$, Western blots of rat cultured TGNs and CGNs after $7 \mathrm{~d}$ in vitro using SV2 isoform-specific antibodies. E, GST-SV2C-L4 protein immobilized on glutathione-Sepharose beads was incubated with EA (SC or DC), BoNT/A or /E (DC) at $4^{\circ} \mathrm{C}$ for $4 \mathrm{~h}$; after washing, the bound protein eluted was analyzed by SDS-PAGE without heating (see Materials and Methods), followed by Western blotting with the antibodies indicated. $\boldsymbol{F}$, A model substrate [GFP-SNAP-25 (134-206)-His6; $13.5 \mu \mathrm{m}$ ] (Wang et al., 2008) was incubated with $25 \mathrm{~nm}$ EA or its parental toxins for $30 \mathrm{~min}$ at $37^{\circ} \mathrm{C}$ and subjected to SDS-PAGE, followed by Coomassie staining. Data plotted are means $\pm \mathrm{SEM} ; n \geq 3$.

confirming that toxin-induced blockade of CGRP release in situ is similar to that seen in TGNs. The current threshold for evoked spiking after exposure to /EA was significantly increased (41.3 \pm $5 \%)$ compared with control neurons with steeper $1 / R_{\text {input }}$ relation at near-threshold depolarization ranges (Fig. 2C,D). To further document the blockade of TRPV1-mediated CGRP release from TGNs by /EA, its effect on CGRP-sensitive parameters of evoked firing in DSNs was evaluated before and after capsaicin application to brainstem slices. In control experiments $(n=6)$, bath application of capsaicin ( $1 \mu \mathrm{M}, 15 \mathrm{~min})$ did not significantly alter the resting membrane current $(-75 \mathrm{mV}$ holding potential; data not shown), consistent with capsaicin acting via TRPV1 expressed exclusively in trigeminal primary afferents (Sugimoto et al., 1997; Bae et al., 2004). In /A-treated neurons, capsaicin caused a clear acceleration of the onset of evoked spiking ( $23 \pm$ $6.5 \%$ reduction of the delay), after $5 \mathrm{~min}$ application $(n=5 ; p<$ 0.05 ), lowered the threshold current for eliciting spikes, and produced a significant increase in the number of spikes (Fig. $5 \mathrm{~A}, \mathrm{D}$ $F)$. Similar to CGRP-induced enhancement of evoked spiking, the effects of capsaicin were pronounced within mild intensities of injected current and were abolished when CGRP8-37 was coapplied with capsaicin (10 min application) (Fig. 5A). Overall, these results suggest that the excitatory action of capsaicin on DSNs is primarily mediated via downstream activation of CGRP1 receptors. In contrast, the enhancement of evoked spiking by capsaicin was strongly attenuated in slices preincubated in /EA $(n=4)$ (Fig. $5 B-E)$. Neither spike delay, the spike number, nor current threshold for eliciting spikes were significantly different in /EA pretreated slices before and after application of capsaicin (10 min application). Similar results were obtained with slow- depolarizing ramp currents in /EA pretreated neurons, showing a greatly suppressed excitatory effect of capsaicin $(n=4)$ (Fig. 5C). Together with observations made in TGNs, these data provide cumulative and convergent evidence for effective blockade of capsaicin-induced CGRP release by /EA but not/A, raising the question as to why /A-cleaved SNAP-25 can mediate CGRP release when induced by activation of TRPV1. Because BoNT/A and /EA bind to the same acceptor and, by extrapolation, the same subpopulation of trigeminal neurons/afferents, it seems likely that the greater effectiveness of /EA can be attributed to a more complete disablement of SNAP-25 than that caused by BoNT/A.

\section{Formation of stable SNARE complexes by /A- but not /E- truncated SNAP-25 highlights that residues 198-206 are dispensable for capsaicin-evoked exocytosis}

The 17 amino acids between the cleavage sites for BoNT/A and /E at the $\mathrm{C}$ terminal of SNAP-25 are required for its high-affinity binding to syntaxin (Bajohrs et al., 2004), although it has been claimed that $\mathrm{N}$-terminal residues $2-82$ are sufficient (Chapman et al., 1994). In view of these conflicting in vitro data obtained with recombinant fusion proteins or tagged fragments, perturbations caused by BoNT/A or /EA to SNARE complex formation in sensory neurons was examined by two-dimensional PAGE and Western blotting. In SDS extracts from non-intoxicated cells, the majorities of syntaxin1, SNAP-25, and VAMP1 were not associated with any SDS-resistant complex (Fig. 6A). This is shown by their migrations in PAGE being unchanged by boiling and matching the mobilities predicted by their molecular masses. However, some SNAP-25 was retarded in complexes varying in 


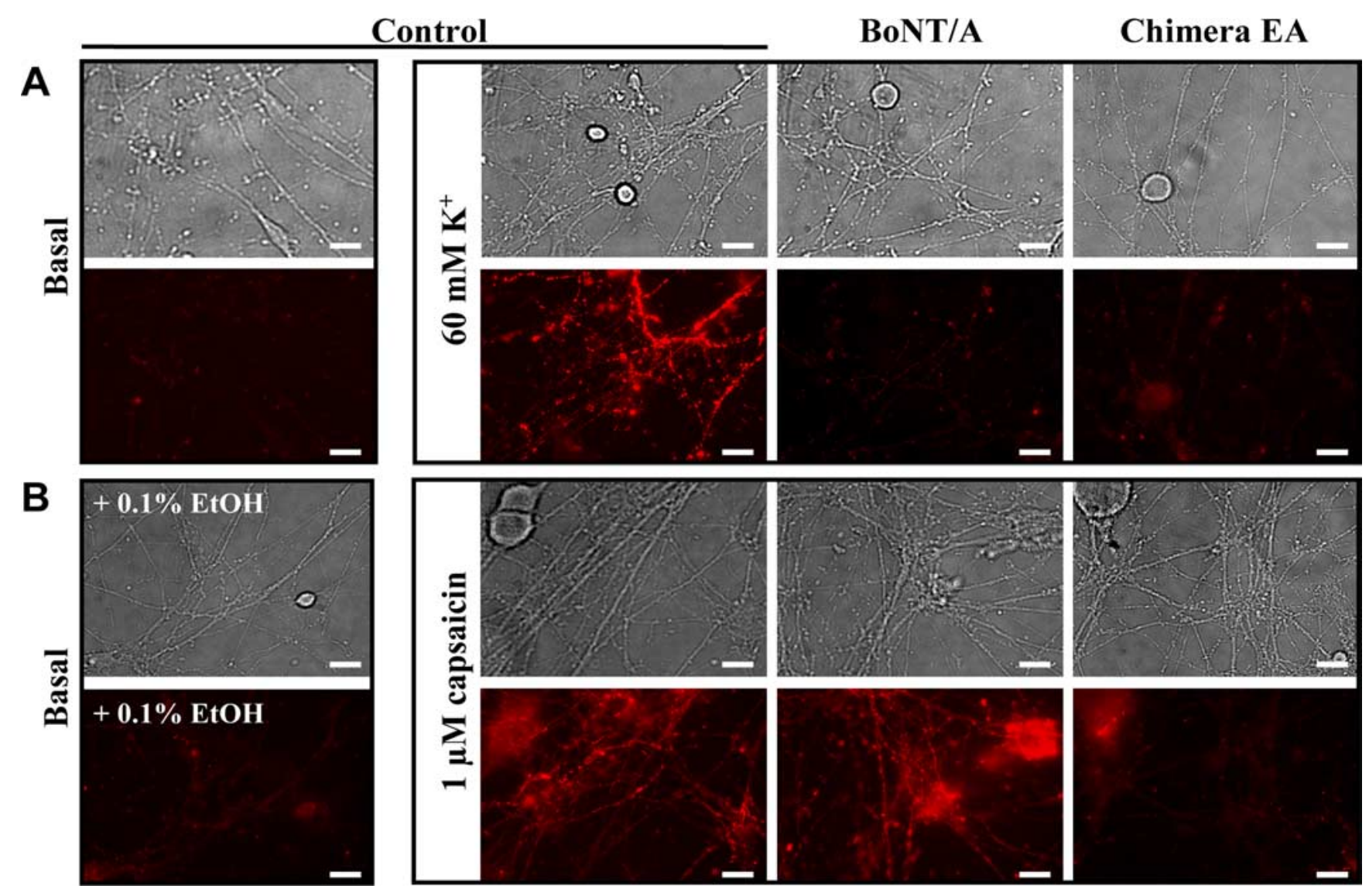

Figure 4. EA and BoNT/A both inhibitK ${ }^{+}$-evoked transfer of synaptotagmin I-containing vesicles to the surface of sensory neurons, whereas only EA blocks the capsaicin-stimulated fusion. TGNs were grown on coverslips for $7 \mathrm{~d}$ in vitro, incubated with or without $100 \mathrm{~nm} \mathrm{EA}$ or BoNT/A for $24 \mathrm{~h}$ before washing and exposure to Syt-Ecto antibody for 15 min in either basal or $60 \mathrm{~mm} \mathrm{~K} \mathrm{C}^{+}(\boldsymbol{A})$ or 1 $\mu \mathrm{m}$ capsaicin (B). Cells were then fixed, and images of the same field were recorded in phase contrast (top panels) or fluorescent mode (bottom panels). The increased fluorescent signal induced by $\mathrm{K}^{+}$depolarization was reduced to basal level by both toxins $(\boldsymbol{A})$; in contrast, the elevated signal elicited by capsaicin remained unaffected by /A but was diminished by EA (B). Scale bar, $20 \mu \mathrm{m}$.

size from $M_{\mathrm{r}}$ of 52,000 to $>288,000$ and, particularly, in the 104,000-288,000 range. Likewise, syntaxin1 was detected in bands with $M_{\mathrm{r}}$ between 52,000 and $>288,000$, whereas there were only weak immunosignals for VAMP1 (Fig. 6A), restricted to the $M_{\mathrm{r}}$ of 104,000-205,000 range. Stimulation of TGNs with capsaicin only moderately increased the amounts of SDS-resistant complexes (data not shown). In cells exposed for $24 \mathrm{~h}$ to $100 \mathrm{nM}$ BoNT/A, the bulk of SNAP-25 was truncated (Fig. $6 \mathrm{~A}$ ); notably, both cleaved (SNAP-25A) and uncleaved SNAP-25 were detected in SDS-resistant complexes that also contained syntaxin 1 and a trace of VAMP1, in similar ratios as in the non-intoxicated cells. Clearly, SNAP-25A can form SDS-resistant complexes with its SNARE partners. In contrast, in /EA-treated TGNs, only traces of /E-truncated SNAP-25 (SNAP-25E) and syntaxin1 were found in the 74,000-146,000 range (Fig. 6A); minute amounts of uncleaved SNAP-25 were also present, but VAMP1 could not be detected. The inability of SNAP-25E to form complexes in sensory TGNs, unlike SNAP-25A, seems a likely explanation for the more extensive inhibition of exocytosis by /EA than BoNT/A.

The apparent scarcity of VAMP1 in SDS-resistant SNARE complexes in TGNs was probed using BoNT/D because it cleaves VAMP1-VAMP3 and inhibits evoked CGRP release (Meng et al., 2007). After treatment with this toxin, the amount of noncomplexed intact VAMP1 was reduced by $80 \%$, and it could not be detected in SDS-resistant complexes (Fig. 6B). Nevertheless, syntaxin:SNAP-25 complexes were only slightly diminished compared with toxin-free controls, supporting the notion that they lack VAMPs. Simultaneous exposure to both BoNT/A and /D resulted in cleavage of $>50 \%$ of the SNAP- 25 and $80 \%$ of VAMP1; notably, only intact SNAP-25 was detectable in these complexes (with just a trace of SNAP-25A), a striking contrast to the occurrence of SNAP-25A in TGNs exposed to BoNT/A alone (Fig. 6A). This suggests that association of SNAP-25A with syntaxin 1 requires the presence of VAMP1; its apparent absence from the SDS-resistant complexes is most likely attributable to VAMP1 weakly associating with syntaxin 1 or SNAP-25A but being subsequently dissociated by SDS. If stable binding with syntaxin underlies the ability of SNAP-25A to support CGRP release in TGNs, VAMP is essential for this to occur.

Sensitivity to $\left[\mathrm{Ca}^{2+}\right]_{\mathrm{o}}$ of CGRP exocytosis triggered by $\mathrm{K}^{+}$ from TGNs is reduced by BoNT/A or /EA, but their response to capsaicin is only blocked by /EA

The $\mathrm{C}$ terminus of SNAP-25 has been implicated in $\mathrm{Ca}^{2+}$ dependent binding to synaptotagmin and the triggering of vesicle fusion (Gerona et al., 2000). However, after deleting part of that region with $\mathrm{BoNT} / \mathrm{A}$, the loss of this interaction can be restored on elevating $\left[\mathrm{Ca}^{2+}\right]_{\mathrm{i}}$, suggesting that the toxin reduces the sensitivity of the $\mathrm{Ca}^{2+}$ sensor. Likewise, neurotransmission recovers in BoNT/A-paralyzed nerve terminals after treatments that open $\mathrm{Ca}^{2+}$ channels and/or increase membrane $\mathrm{Ca}^{2+}$ permeability (Molgó and Thesleff, 1984; Adler et al., 2000). To test whether an increase in $\left[\mathrm{Ca}^{2+}\right]_{\mathrm{i}}$ by capsaicin overcomes the postulated reduction in $\mathrm{Ca}^{2+}$ sensitivity, the effects of BoNT/A or /EA on the 
$\left[\mathrm{Ca}^{2+}\right]$ dependency and amounts of CGRP release from TGNs were quantified. Notably, $\left[\mathrm{Ca}^{2+}\right]_{\mathrm{o}}$ dependencies of the responses to $\mathrm{K}^{+}$and capsaicin were similar in control cells (Fig. 7A,B) except for higher basal release in the presence of capsaicin; the $\mathrm{EC}_{50}$ values for $\left[\mathrm{Ca}^{2+}\right]_{0}$ were 0.6 and $0.9 \mathrm{mM}$, respectively, whereas ECMAX was $\sim 5 \mathrm{~mm}$ in both cases. CGRP release elicited by either stimulus (Fig. $7 A, B)$ was effectively inhibited by /EA at $\left[\mathrm{Ca}^{2+}\right]$ up to $5 \mathrm{~mm}$, with some lessening at higher concentrations; the $\mathrm{Ca}^{2+}$ sensitivity was, apparently, reduced. /A poorly inhibited responses to capsaicin even at low external $\left[\mathrm{Ca}^{2+}\right]$ (Fig. $7 B$ ), whereas it virtually abolished $\mathrm{K}^{+}$-evoked CGRP release in $1 \mathrm{~mm}\left[\mathrm{Ca}^{2+}\right]_{\mathrm{o}}$ or less (Fig. $7 A$ ), but additional increments in $\left[\mathrm{Ca}^{2+}\right]_{\mathrm{o}}$ yielded levels approaching that of the control (Fig. 7A). Assuming 100\% recovery from inhibition could be achieved, the $\mathrm{EC}_{50}$ of $\mathrm{Ca}^{2+}$ for $\mathrm{K}^{+}$- evoked release from /A-treated cells was $\sim 15 \mathrm{~mm}$, an $\sim 30$-fold reduction in sensitivity. Conversely, /A did not alter the $\left[\mathrm{Ca}^{2+}\right]_{0}$ dependency of capsaicin-evoked CGRP release $\left(\mathrm{EC}_{50} \sim 1 \mathrm{~mm}\right)$, despite causing a decrement in exocytosis in response to each $\left[\mathrm{Ca}^{2+}\right]_{\mathrm{o}}$ (Fig. $7 B$ ). Notably, the latter finding is difficult to reconcile with BoNT/A directly lowering sensitivity of the $\mathrm{Ca}^{2+}$-sensing mechanism. To gain insights into this differential reversibility, the influence of altering $\left[\mathrm{Ca}^{2+}\right]_{i}$ on the restoration of CGRP release from inhibition by the toxins was investigated using a $\mathrm{Ca}^{2+}$ ionophore. TGNs treated with /A or /EA resulted in 70-80\% inhibition of $\mathrm{K}^{+}$elicited CGRP release (Fig. 7C). Ionomycin overcame the inhibition of $\mathrm{K}^{+}$stimulated exocytosis by toxins to a far greater extent in cells pretreated with /A than /EA ( $\sim 70$ and $\sim 20 \%$, respectively) (Fig. $7 C$ ). Notably, in $\mathrm{Ca}^{2+}$-free medium, neither ionomycin nor $\mathrm{K}^{+}$elicited any release from toxin-treated cells, indicating a requirement for extracellular $\mathrm{Ca}^{2+}$ (Fig. 7C).

A more prolonged increase in $\left[\mathrm{Ca}^{2+}\right]_{\mathrm{i}}$ induced by capsaicin than $\mathrm{K}^{+}$depolarization affords CGRP exocytosis from TGNs treated with BoNT/A but not /EA

A basis for such notable differences in the susceptibilities to /A and /EA of responses to $\mathrm{K}^{+}$depolarization and capsaicin was sought using a $\mathrm{Ca}^{2+}$-indicator dye, Fluo-4 AM, with monitoring of the $\mathrm{Ca}^{2+}$ elevation in the cell bodies of randomly selected TGNs. In control cells, there was a sharp increase in $\left[\mathrm{Ca}^{2+}\right]_{\mathrm{i}}$ immediately after $\mathrm{K}^{+}$-induced depolarization (Fig. 8A), followed by decay of the $\mathrm{Ca}^{2+}$ level to $40 \%$ of the peak increase within $\sim 5 \mathrm{~min}$ (Fig. $8 \mathrm{~A}$, inset, normalized data). An initial sharp but sustained increase in $\left[\mathrm{Ca}^{2+}\right]_{\mathrm{i}}$ was elicited with capsaicin in the vast majority of cells, presumably the TRPV1-positive neurons. Although the maximal increment in intensity was lower than that evoked by $\mathrm{K}^{+}$(Fig. $8 \mathrm{~A}$ ), elevation of the $\mathrm{Ca}^{2+}$ produced by capsaicin persisted at a significantly higher level, with a
$40 \%$ decrease from the peak at $\sim 25$ min (Fig. 8A). Consistent with this, capsaicin elicited a faster, more persistent and larger (more than twofold) accumulation of ${ }^{45} \mathrm{Ca}^{2+}$ than that induced by $\mathrm{K}^{+}$depolarization (Fig. $8 \mathrm{~B}$ ). Notably, pretreatment of TGNs with /A retarded the capsaicin-evoked exocytosis of CGRP ( $p<$ $0.05 ; t=2 \mathrm{~min}$ ) (Fig. $8 C$ ), but the maximum amount finally released approximated to that from the control $(t=32 \mathrm{~min}$ ), highlighting how a prolonged elevation of $\left[\mathrm{Ca}^{2+}\right]_{i}$ alleviates the inhibition by/A. It is noteworthy that neither the $\mathrm{Ca}^{2+}$ dynamics nor ${ }^{45} \mathrm{Ca}^{2+}$ uptake were altered by treating the TGNs overnight with $100 \mathrm{~nm} / \mathrm{A}$ (data not shown). Collectively, our results can be reconciled with the relative stabilities of SNARE complexes containing full-length or BoNT/A- or /EA-truncated SNAP-25 and the longer duration of elevated $\left[\mathrm{Ca}^{2+}\right]_{\mathrm{i}}$ elicited by capsaicin compared with other stimuli.

\section{Discussion}

The present study shows that basal and evoked CGRP release enhance the electroresponsiveness of relay sensory neurons in brainstem TNC via a CGRP1 receptor-mediated mechanism. Use of a recombinant BoNT chimera together with sensitive biochemical assays, electrophysiological recordings, and fluoromet- 
Mr before boiling $(\mathrm{kD})$
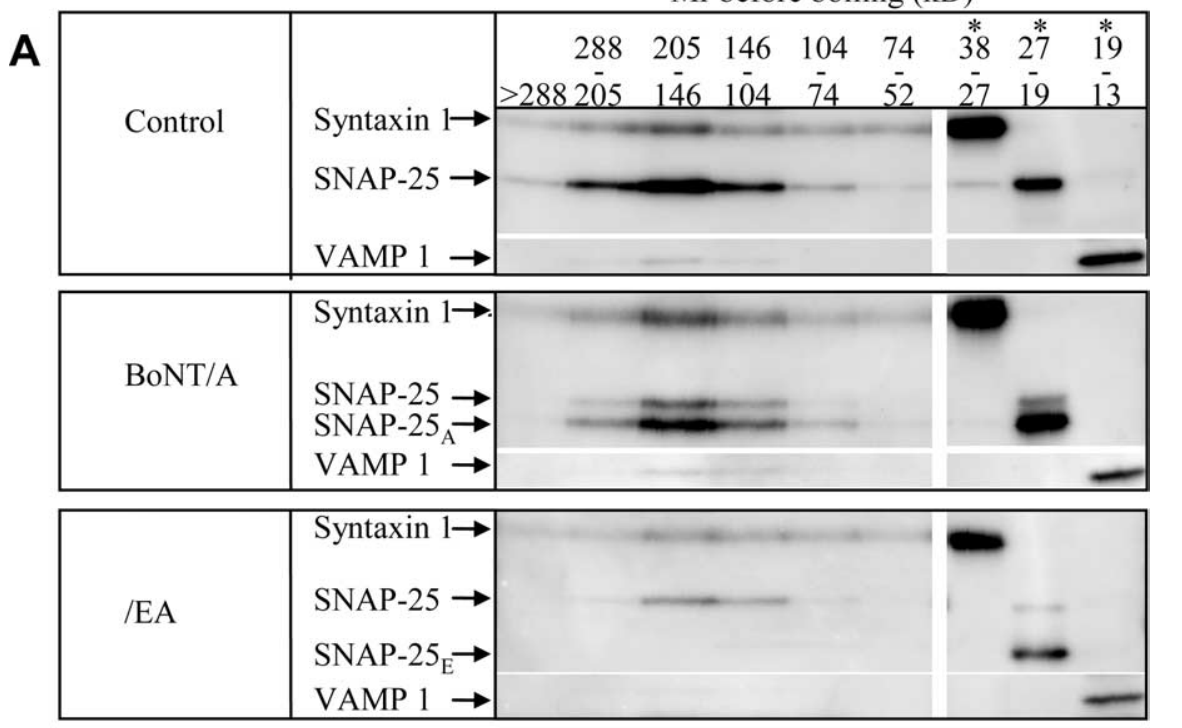

B
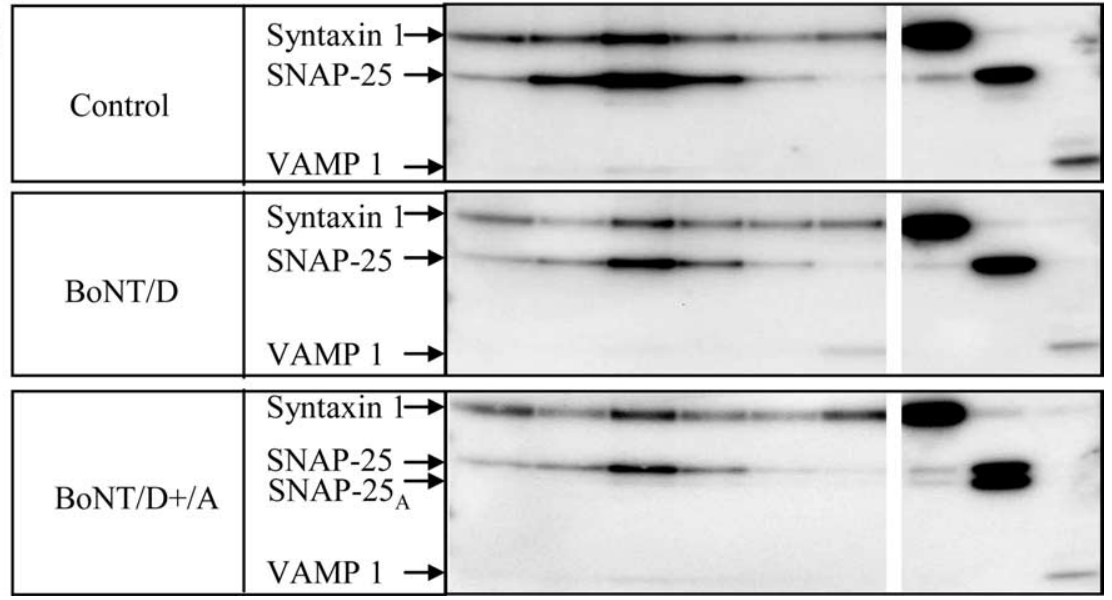

Figure 6. The presence of BoNT/A- but not /E-truncated SNAP-25 in SDS-resistant SNARE complexes requires intact VAMP. TGNs at $7 \mathrm{~d}$ in vitro were incubated for $24 \mathrm{~h}$ in the absence or presence of $100 \mathrm{~nm}$ of BoNT/A or EA $(\boldsymbol{A}), \mathrm{BoNT} / \mathrm{D}$ or $/ \mathrm{D}$ plus $/ \mathrm{A}(\boldsymbol{B})$. After toxin removal, cells were stimulated with $1 \mu \mathrm{m}$ capsaicin in the presence of $2.5 \mathrm{~mm} \mathrm{Ca}^{2+}$ for $30 \mathrm{~min}$, before lysis in $2 \times \mathrm{LDS}$ sample buffer and SDS-PAGE (without boiling). Gel sections containing the separated proteins were excised according to migration distance and extracted by boiling in LDS sample buffer before re-electrophoresis and immunoblot analysis with antibodies specific for syntaxin, SNAP-25 (intact and cleaved), or VAMP 1 (see Materials and Methods). Images are representative of results obtained on three independent occasions; ${ }^{*}$ indicates $20 \%$ of sample was used in these lanes $(\boldsymbol{A}, \boldsymbol{B})$.

ric $\left[\mathrm{Ca}^{2+}\right]_{\mathrm{i}}$ measurements revealed involvement of SNAP-25 in spontaneous and evoked CGRP exocytosis, with important implications for synaptic communication between trigeminal sensory neurons. In light of the well established proinflammatory activity of CGRP and its direct involvement in migraine (Fanciullacci et al., 1995; Doods et al., 2007), our data yield new information pertinent to the mechanism of chronic pain and provide a scientific basis for using BoNT variants as therapeutics for chronic pain and neuroinflammatory disorders.

\section{Blockade of basal CGRP drive by BoNT/A or /EA and its effect in TNC}

It is established here that the basal CGRP drive enhances the excitability of sensory neurons in TNC, an effect abolished by BoNT/A or /EA. Our immunofluorescence staining (Fig. 1A) confirmed previous findings (Bae et al., 2004) of dense CGRPpositive projections within TNCs. The substantial excitatory effects of spontaneously released and bath-applied CGRP on DSNs suggest its potential role in central nociceptive sensitization via an overall increase in responsiveness of a group of TNC sensory neurons, presumably attributable to inhibition of transient, voltage-activated conductance(s). Indeed, the excessive release of CGRP through suppression of depolarization-induced transient conductance could convert subthreshold synaptic "noise" into signals in these projecting neurons, facilitating transfer of nociceptive information to higher brain structures. The excitatory effect of CGRP appears to be mediated via activation of CGRP1 receptors (Poyner, 1995) because it was prevented by CGRP8-37. These findings along with previous in vivo studies, showing its significant blockade of spontaneous spiking activity of sensory neurons in the trigeminal complex (Fischer et al., 2005), indicate that there is adequate scope for elevated release of this peptide to induce central nociceptive sensitization.

The demonstrated ability of BoNT/A and /EA to abolish resting release of CGRP, as reflected by change in the basal CGRP drive and appreciable cleavage of SNAP-25 in the slices studied (J. Meng, S. V. Ovsepian, J. Wang, and J. O. Dolly unpublished data), is especially important in the context of using BOTOX as a possible therapeutic for chronic pain. The failure of BoNT/A to lower the basal release of CGRP in TGNs (Durham et al., 2004) may have arisen from the higher $\left[\mathrm{Ca}^{2+}\right]_{\mathrm{o}}$ used or, perhaps, reflect possible differences between cultured TGNs and slices.

\section{TRPV1 activation mimics the CGRP- induced excitation of TNC sensory neurons, an effect blocked by /EA but not BoNT/A}

An exclusive capacity of /EA for blocking both $\mathrm{K}^{+}$- and capsaicin-induced CGRP release from TGNs, whereas /A only inhibits $\mathrm{K}^{+}$-evoked exocytosis, emphasizes a fundamental difference between these two stimuli (see below). Like CGRP, capsaicin excites DSNs; it most likely activates TRPV1 on CGRP-positive central terminals of trigeminal afferents (Sugimoto et al., 1997; Bae et al., 2004), leading to CGRP release. The presynaptic pattern of TRPV1 expression is also consistent with the fact that no changes in membrane current or AP amplitude in DSNs have been seen during application of capsaicin. Although blockade of $\mathrm{Kv}$ channels by capsaicin has been reported, this only occurs at much higher concentrations (Kuenzi and Dale, 1996; Gutman et al., 2005) than used herein. Blockade by CGRP8-37 of the capsaicin effect on DSNs further supports the indirect effect of capsaicin via activation of presynaptic TRPV1, leading to enhancement of CGRP drive. Like CGRP, capsaicin causes a decrease in the latency of spiking, an overall increase in spike number and a reduction of stimulus threshold for spiking. In contrast to /A, slices exposed to /EA did not show significant changes in evoked firing during capsaicin-induced activation of TRPV1. Similar data were obtained with capsaicin when slow ramps were used for 
stimulation, a protocol that more closely reflects the in vivo time-variable synaptic currents (Schwindt and Crill, 1999). In summary, both /A and /EA effectively suppress the basal CGRP drive in TNC but only /EA blocks capsaicin-induced DSN excitation mediated via CGRP1 receptors.

\section{Molecular basis for the inhibition by /EA of capsaicin-triggered CGRP exocytosis}

The observed sparsity of acceptors for BoNT/E on TGNs explained its inability to block CGRP exocytosis from these neurons and highlighted a need to use /EA in the present investigation. This strategy was based on the reported interaction of $\mathrm{H}_{\mathrm{C}} / \mathrm{A}$ with SV2C (Mahrhold et al., 2006), a feature that was retained in the EA chimera. Consistent with SV2C being the most abundant isoform in TGNs, these cells readily internalized the chimera culminating in SNAP-25 cleavage and blockade of capsaicin-evoked CGRP release, as well as recycling of synaptotagmin1-containing vesicles. Such effects of EA confirmed a requirement for SNAP-25 in capsaicinelicited peptide release from TGNs. Moreover, a molecular basis for its involvement was unveiled by the inability of /EAcleaved SNAP-25 to form a stable complex with syntaxin 1, unlike SNAP-25A. This concurs with in vitro studies showing that BoNT/E more effectively reduced the stability of ternary SNARE complexes than /A (Hayashi et al., 1994), an effect attributable to only three of the nine residues removed by /A being involved in coiled-coil formation, whereas all of the extra 17 residues removed by BoNT/E are required (Sutton et al., 1998). Syntaxin:SNAP-25 complexes are known to bind VAMP and form a meta-stable ternary complex, before $\mathrm{Ca}^{2+}$ triggers a rapid "zippering-up" to drive membrane fusion (Wojcik and Brose, 2007). Hence, one possible interpretation of the exocytotic response to capsaicin of /A-treated TGNs is that pre-fusion complexes are destabilized, as reflected by VAMP being needed for syntaxin:SNAP-25A to acquire resistance to SDS. Consequently, the probability of vesicle fusion is reduced by /A (Fig. 8C), and exocytosis can only be elicited by prolonged $\left[\mathrm{Ca}^{2+}\right]$ signals. This deduction is fully consistent with the finding that, given sufficient time, capsaicin elicits as much CGRP release from /A-treated cells as from controls.

If SNAP-25A retains some functionality, how does BoNT/A block the secretory responses to $\mathrm{K}^{+}$depolarization (or bradykinin) in TGNs and CGRP signaling in the TNC? It has been postulated that BoNT/A inhibits release by lowering the affinity of the $\mathrm{Ca}^{2+}$ sensor, thereby reducing exocytosis. Indeed, $\mathrm{Ca}^{2+}$ enhances binding of synaptotagmin (the putative $\mathrm{Ca}^{2+}$ sensor) to SNAP-25 in vitro (Gerona et al., 2000), albeit requiring $\sim 100$ fold higher concentration than needed to trigger exocytosis; nevertheless, the /A truncation of SNAP-25 reduced synaptotagmin binding, an effect overcome by further raising $\left[\mathrm{Ca}^{2+}\right]$ (Gerona et
B

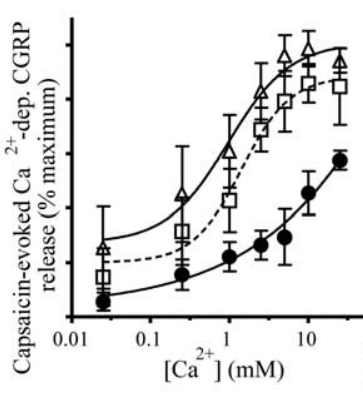

C

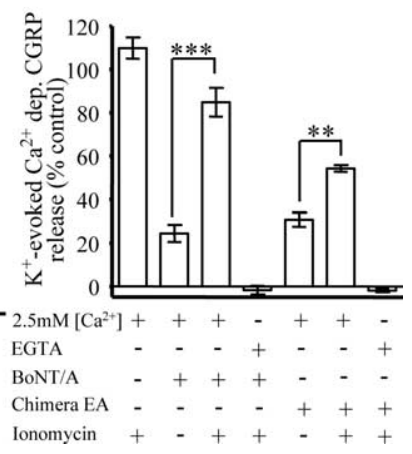

Figure 7. Increasing $\left[\mathrm{Ca}^{2+}\right]_{0}$ reveals differences in the effects of BoNT/A and EA on the $\mathrm{Ca}^{2+}$ dependency of CGRP release from - or capsaicin-stimulated cells: ionomycin reverses the inhibition by /A or /EA of exocytosis evoked by $\mathrm{K}^{+}$depolarization. TGNs at $7 \mathrm{~d}$ in vitro were exposed to $100 \mathrm{~nm}$ BoNT/A $(\boldsymbol{A}, \boldsymbol{B}, \square$ or as indicated in $\boldsymbol{C})$ or $\mathrm{EA}(\boldsymbol{A}, \boldsymbol{B}, \mathbf{\square}$, or as indicated in $\boldsymbol{C})$ at $37^{\circ} \mathrm{C}$ for $24 \mathrm{~h}$

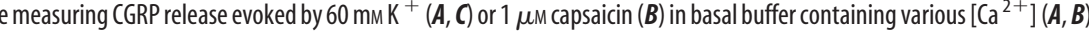
were normalized to the maximum level (in $25 \mathrm{mM} \mathrm{Ca}^{2+}$ ) for toxin-free controls $(\triangle)$. Vehicle for ionomycin $(0.05 \%$ DMSO) was included. Data plotted are means \pm SEM; $n \geq 3$; Student's unpaired $t$ test: ${ }^{* *} p<0.01,{ }^{* * *} p<0.001$.
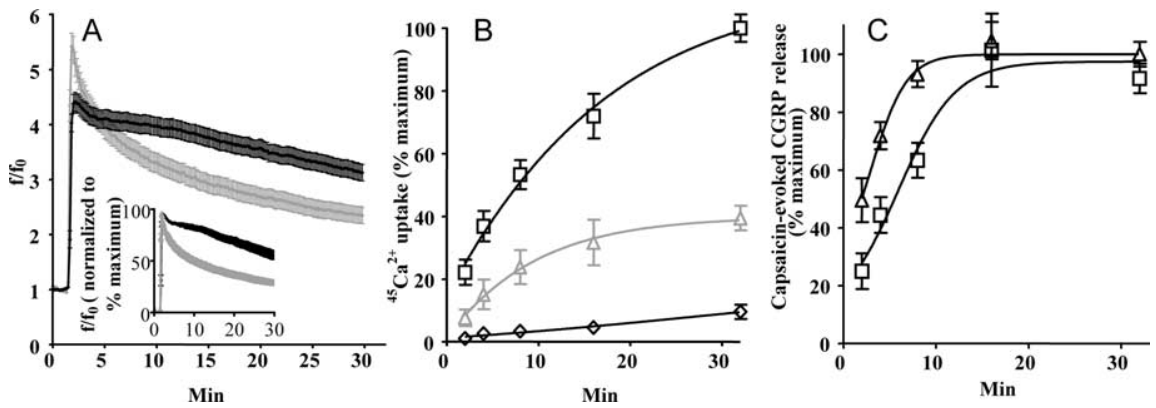

Figure 8. Capsaicin induces a more prolonged increase in $\left[\mathrm{Ca}^{2+}\right]_{\mathrm{i}}$ and greater uptake of ${ }^{45} \mathrm{Ca}^{2+}$ than $\mathrm{K}^{+}$depolarization: BoNT/A retards capsaicin-triggered (GRP release. $A$, Fluorescent readings $(f)$, taken every 10 s over 30 min, are plotted relative to the initial value at $t=0 \mathrm{~min}\left(f_{0}\right)$ for TGNs recorded under continuous stimulation by $60 \mathrm{~mm}\left[\mathrm{~K}^{+}\right]$(gray) or $1 \mu \mathrm{m}$ capsaicin in basal ( measured at different times after exposure to the isotope in $3.5 \mathrm{~mm} \mathrm{~K}^{+}(\diamond) 1$ um capsaicin $(\square)$ or $60 \mathrm{~mm} \mathrm{~K}^{+}(\triangle)$. After extensive washing, the cells were solubilized in $0.1 \%$ SDS before counting in a $\beta$ spectrometer. Capsaicin-induced ${ }^{45} \mathrm{Ca}^{2+}$ uptake after $32 \mathrm{~min}$ was $\sim 4 \mathrm{pmol} /$ well in a typical experiment. C, CGRP release elicited by capsaicin was monitored from control cells $(\triangle)$ or those treated for $24 \mathrm{~h}$ with $100 \mathrm{~nm}$ BoNT/A $(\square)$, as described in Figure 3. All data plotted in $\boldsymbol{B}$ and $\boldsymbol{C}$ are means \pm SEM; $n \geq 3$.

al., 2000). However, $\mathrm{Ca}^{2+}$ stimulates synaptotagmin to bind three aspartic acid residues in SNAP-25 (D179, D186, and D193), none of which are removed by /A, but /EA cleaves off the latter two (Zhang et al., 2002). In line with this, our observation that /A does not alter the $\mathrm{Ca}^{2+}$ dependency of capsaicin-evoked CGRP release from TGNs is in general accord with data on permeabilized neuroendocrine cells wherein $\left[\mathrm{Ca}^{2+}\right]_{\mathrm{i}}$ was tightly buffered (Gerona et al., 2000; Lawrence and Dolly, 2002). Furthermore, the spatial and temporal patterns of $\left[\mathrm{Ca}^{2+}\right]_{i}$ also influence the amount and rate of exocytosis from secretory cells (Augustine and Neher, 1992). Capsaicin induced a more persistent rise in $\mathrm{Ca}^{2+}$ levels than $\mathrm{K}^{+}$, consistent with observations on cultured sensory neurons (Dedov and Roufogalis, 2000; Karai et al., 2004), and caused twofold more uptake of ${ }^{45} \mathrm{Ca}^{2+}$. Such a prolonged elevation in $\left[\mathrm{Ca}^{2+}\right]_{\mathrm{i}}$ is likely to overcome the BoNT/A-induced delay in vesicle fusion and its associated slowing of the release rate (Sakaba et al., 2005); this is attributed to /A destabilizing a prefusion SNARE complex (Fig. 6) required for the initial synchronized exocytosis (Xu et al., 1998; Wojcik and Brose, 2007). The spatial localization of $\mathrm{K}^{+}$-induced $\left[\mathrm{Ca}^{2+}\right]_{\mathrm{i}}$ microdomains may 
be distant from secretory vesicles, especially large-dense core granules that contain CGRP, whereas prolonged elevation of $\left[\mathrm{Ca}^{2+}\right]_{\mathrm{i}}$ produced by capsaicin may more effectively trigger this exocytosis, despite the retarding effects of BoNT/A. Future indepth studies to address this question are warranted, perhaps, using a combination of patch-clamp, high-resolution $\mathrm{Ca}^{2+}$ imaging and amperometry of vesicle-loaded oxidizable "false transmitters," similar to that described for other cells (Chow et al., 1994; Zhang and Zhou, 2002; Sakaba et al., 2005).

\section{References}

Adler M, Capacio B, Deshpande SS (2000) Antagonism of botulinum toxin A-mediated muscle paralysis by 3, 4-diaminopyridine delivered via osmotic minipumps. Toxicon 38:1381-1388.

Augustine GJ, Neher E (1992) Calcium requirements for secretion in bovine chromaffin cells. J Physiol 450:247-271.

Bae YC, Oh JM, Hwang SJ, Shigenaga Y, Valtschanoff JG (2004) Expression of vanilloid receptor TRPV1 in the rat trigeminal sensory nuclei. J Comp Neurol 478:62-71.

Bajohrs M, Rickman C, Binz T, Davletov B (2004) A molecular basis underlying differences in the toxicity of botulinum serotypes A and E. EMBO Rep 5:1090-1095.

Ballantyne JC, Mao J (2003) Opioid therapy for chronic pain. N Engl J Med 349:1943-1953.

Binder WJ, Brin MF, Blitzer A, Schoenrock LD, Pogoda JM (2000) Botulinum toxin type A (BOTOX) for treatment of migraine headaches: an open-label study. Otolaryngol Head Neck Surg 123:669-676.

Black PH (2002) Stress and the inflammatory response: a review of neurogenic inflammation. Brain Behav Immun 16:622-653.

Bolay H, Reuter U, Dunn AK, Huang Z, Boas DA, Moskowitz MA (2002) Intrinsic brain activity triggers trigeminal meningeal afferents in a migraine model. Nat Med 8:136-142.

Breivik H, Collett B, Ventafridda V, Cohen R, Gallacher D (2006) Survey of chronic pain in Europe: prevalence, impact on daily life, and treatment. Eur J Pain 10:287-333.

Burstein R, Yarnitsky D, Goor-Aryeh I, Ransil BJ, Bajwa ZH (2000) An association between migraine and cutaneous allodynia. Ann Neurol $47: 614-624$.

Carstens E, Kuenzler N, Handwerker HO (1998) Activation of neurons in rat trigeminal subnucleus caudalis by different irritant chemicals applied to oral or ocular mucosa. J Neurophysiol 80:465-492.

Chapman ER, An S, Barton N, Jahn R (1994) SNAP-25, a t-SNARE which binds to both syntaxin and synaptobrevin via domains that may form coiled coils. J Biol Chem 269:27427-27432.

Chow RH, Klingauf J, Neher E (1994) Time course of $\mathrm{Ca}^{2+}$ concentration triggering exocytosis in neuroendocrine cells. Proc Natl Acad Sci USA 91:12765-12769.

Dedov VN, Roufogalis BD (2000) Mitochondrial calcium accumulation following activation of vanilloid (VR1) receptors by capsaicin in dorsal root ganglion neurons. Neuroscience 95:183-188.

de Paiva A, Ashton AC, Foran P, Schiavo G, Montecucco C, Dolly JO (1993) Botulinum A like type B and tetanus toxins fulfils criteria for being a zinc-dependent protease. J Neurochem 61:2338-2341.

Dong M, Yeh F, Tepp WH, Dean C, Johnson EA, Janz R, Chapman ER (2006) SV2 is the protein receptor for botulinum neurotoxin A. Science 312:592-596.

Dong M, Liu H, Tepp WH, Johnson EA, Janz R, Chapman ER (2008) Glycosylated SV2A and SV2B mediate the entry of botulinum neurotoxin E into neurons. Mol Biol Cell 19:5226-5237.

Doods H, Arndt K, Rudolf K, Just S (2007) CGRP antagonists: unravelling the role of CGRP in migraine. Trends Pharmacol Sci 28:580-587.

Durham PL, Cady R, Cady R (2004) Regulation of calcitonin gene-related peptide secretion from trigeminal nerve cells by botulinum toxin type A: implications for migraine therapy. Headache 44:35-42, discussion $42-43$.

Fanciullacci M, Alessandri M, Figini M, Geppetti P, Michelacci S (1995) Increase in plasma calcitonin gene-related peptide from the extracerebral circulation during nitroglycerin-induced cluster headache attack. Pain 60:119-123.

Ferrari MD, Roon KI, Lipton RB, Goadsby PJ (2001) Oral triptans (seroto- nin 5-HT(1B/1D) agonists) in acute migraine treatment: a meta-analysis of 53 trials. Lancet 358:1668-1675.

Fischer MJ, Koulchitsky S, Messlinger K (2005) The nonpeptide calcitonin gene-related peptide receptor antagonist BIBN4096BS lowers the activity of neurons with meningeal input in the rat spinal trigeminal nucleus. J Neurosci 25:5877-5883.

Foran PG, Mohammed N, Lisk GO, Nagwaney S, Lawrence GW, Johnson E, Smith L, Aoki KR, Dolly JO (2003) Evaluation of the therapeutic usefulness of botulinum neurotoxin B, C1, E, and F compared with the long lasting type A. Basis for distinct durations of inhibition of exocytosis in central neurons. J Biol Chem 278:1363-1371.

Gerona RR, Larsen EC, Kowalchyk JA, Martin TF (2000) The C terminus of SNAP25 is essential for $\mathrm{Ca}^{2+}$-dependent binding of synaptotagmin to SNARE complexes. J Biol Chem 275:6328-6336.

Goadsby PJ, Edvinsson L (1993) The trigeminovascular system and migraine: studies characterizing cerebrovascular and neuropeptide changes seen in humans and cats. Ann Neurol 33:48-56.

Goadsby PJ, Edvinsson L, Ekman R (1990) Vasoactive peptide release in the extracerebral circulation of humans during migraine headache. Ann Neurol 28:183-187.

Gulbenkian S, Uddman R, Edvinsson L (2001) Neuronal messengers in the human cerebral circulation. Peptides 22:995-1007.

Gutman GA, Chandy KG, Grissmer S, Lazdunski M, McKinnon D, Pardo LA, Robertson GA, Rudy B, Sanguinetti MC, Stühmer W, Wang X (2005) International Union of Pharmacology. LIII. Nomenclature and molecular relationships of voltage-gated potassium channels. Pharmacol Rev 57:473-508.

Hamill OP, Marty A, Neher E, Sakmann B, Sigworth FJ (1981) Improved patch-clamp techniques for high-resolution current recording from cells and cell-free membrane patches. Pflugers Arch 391:85-100.

Hayashi T, McMahon H, Yamasaki S, Binz T, Hata Y, Südhof TC, Niemann H (1994) Synaptic vesicle membrane fusion complex: action of clostridial neurotoxins on assembly. EMBO J 13:5051-5061.

Hiura A, Nasu F, Ishizuka H (1999) FRAP-positive and capsaicin-sensitive terminals in the substantia gelatinosa of the mouse spinal trigeminal nucleus caudalis. Okajimas Folia Anat Jpn 76:33-40.

Kárai LJ, Russell JT, Iadarola MJ, Oláh Z (2004) Vanilloid receptor 1 regulates multiple calcium compartments and contributes to $\mathrm{Ca}^{2+}$-induced $\mathrm{Ca}^{2+}$ release in sensory neurons. J Biol Chem 279:16377-16387.

Keller JE, Cai F, Neale EA (2004) Uptake of botulinum neurotoxin into cultured neurons. Biochemistry 43:526-532.

Kuenzi FM, Dale N (1996) Effect of capsaicin and analogues on potassium and calcium currents and vanilloid receptors in Xenopus embryo spinal neurones. Br J Pharmacol 119:81-90.

Lawrence GW, Dolly JO (2002) $\mathrm{Ca}^{2+}$-induced changes in SNAREs and synaptotagmin I correlate with triggered exocytosis from chromaffin cells: insights gleaned into the signal transduction using trypsin and botulinum toxins. J Cell Sci 115:2791-2800.

Mahrhold S, Rummel A, Bigalke H, Davletov B, Binz T (2006) The synaptic vesicle protein $2 \mathrm{C}$ mediates the uptake of botulinum neurotoxin $\mathrm{A}$ into phrenic nerves. FEBS Lett 580:2011-2014.

Mauskop A (2002) The use of botulinum toxin in the treatment of headaches. Curr Pain Headache Rep 6:320-323.

Meng J, Wang J, Lawrence G, Dolly JO (2007) Synaptobrevin I mediates exocytosis of CGRP from sensory neurons and inhibition by botulinum toxins reflects their anti-nociceptive potential. J Cell Sci 120:2864-2874.

Molgó J, Thesleff S (1984) Studies on the mode of action of botulinum toxin type A at the frog neuromuscular junction. Brain Res 297:309-316.

Naumann M, So Y, Argoff CE, Childers MK, Dykstra DD, Gronseth GS, Jabbari B, Kaufmann HC, Schurch B, Silberstein SD, Simpson DM (2008) Assessment: botulinum neurotoxin in the treatment of autonomic disorders and pain (an evidence-based review): report of the Therapeutics and Technology Assessment Subcommittee of the American Academy of Neurology. Neurology 70:1707-1714.

Olesen J, Lipton RB (2004) Headache classification update 2004. Curr Opin Neurol 17:275-282.

Olesen J, Diener HC, Husstedt IW, Goadsby PJ, Hall D, Meier U, Pollentier S, Lesko LM (2004) Calcitonin gene-related peptide receptor antagonist BIBN 4096 BS for the acute treatment of migraine. N Engl J Med 350:1104-1110.

Ovsepian SV, Friel DD (2008) The leaner P/Q-type calcium channel muta- 
tion renders cerebellar Purkinje neurons hyper-excitable and eliminates $\mathrm{Ca}^{2+}-\mathrm{Na}^{+}$spike bursts. Eur J Neurosci 27:93-103.

Poyner D (1995) Pharmacology of receptors for calcitonin gene-related peptide and amylin. Trends Pharmacol Sci 16:424-428.

Roper A, Brown R (2005) Pain and other disorders of somatic sensation, headache, and backache. In: Adams and Victor's principles of neurology, Ed 8 (Roper A, Brown R, eds), pp 109-168. Columbus, OH: McGraw-Hill.

Sakaba T, Stein A, Jahn R, Neher E (2005) Distinct kinetic changes in neurotransmitter release after SNARE protein cleavage. Science 309:491-494.

Scholz J, Woolf CJ (2007) The neuropathic pain triad: neurons, immune cells and glia. Nat Neurosci 10:1361-1368.

Schwindt P, Crill W (1999) Mechanisms underlying burst and regular spiking evoked by dendritic depolarization in layer 5 cortical pyramidal neurons. J Neurophysiol 81:1341-1354.

Sedlacek M, Horak M, Vyklický L Jr (2007) Morphology and physiology of lamina I neurons of the caudal part of the trigeminal nucleus. Neuroscience 147:325-333.

Silberstein S, Mathew N, Saper J, Jenkins S (2000) Botulinum toxin type A as a migraine preventive treatment. For the BOTOX Migraine Clinical Research Group. Headache 40:445-450.

Sugimoto T, Fujiyoshi Y, Xiao C, He YF, Ichikawa H (1997) Central projection of calcitonin gene-related peptide (CGRP)- and substance P (SP)immunoreactive trigeminal primary neurons in the rat. J Comp Neurol 378:425-442.
Sutton RB, Fasshauer D, Jahn R, Brunger AT (1998) Crystal structure of a SNARE complex involved in synaptic exocytosis at $2.4 \mathrm{~A}$ resolution. Nature 395:347-353.

Wang J, Meng J, Lawrence GW, Zurawski TH, Sasse A, Bodeker MO, Gilmore MA, Fernández-Salas E, Francis J, Steward LE, Aoki KR, Dolly JO (2008) Novel chimeras of botulinum neurotoxins A and E unveil contributions from the binding, translocation, and protease domains to their functional characteristics. J Biol Chem 283:16993-17002.

Wimalawansa SJ (1996) Calcitonin gene-related peptide and its receptors: molecular genetics, physiology, pathophysiology, and therapeutic potentials. Endocr Rev 17:533-585.

Wojcik SM, Brose N (2007) Regulation of membrane fusion in synaptic excitation-secretion coupling: speed and accuracy matter. Neuron 55:11-24.

Xu T, Binz T, Niemann H, Neher E (1998) Multiple kinetic components of exocytosis distinguished by neurotoxin sensitivity. Nat Neurosci 1:192-200.

Zhang C, Zhou Z (2002) $\mathrm{Ca}^{2+}$-independent but voltage-dependent secretion in mammalian dorsal root ganglion neurons. Nat Neurosci 5:425-430.

Zhang X, Kim-Miller MJ, Fukuda M, Kowalchyk JA, Martin TF (2002) $\mathrm{Ca}^{2+}$-dependent synaptotagmin binding to SNAP-25 is essential for $\mathrm{Ca}^{2+}$-triggered exocytosis. Neuron 34:599-611. 